\title{
Normoalbuminuric kidney impairment in patients with T1DM: insights from annals initiative
}

\author{
Olga Lamacchia ${ }^{1 *}$, Francesca Viazzi ${ }^{2}$, Paola Fioretto ${ }^{3}$, Antonio Mirijello ${ }^{4}$, Carlo Giorda ${ }^{5}$, Antonio Ceriello ${ }^{6,7}$, \\ Giuseppina Russo ${ }^{8}$, Pietro Guida ${ }^{9}$, Roberto Pontremoli ${ }^{2}$ and Salvatore De Cosmo ${ }^{4^{*}}$
}

\begin{abstract}
Background: We described, in a large sample of patients with type 1 diabetes mellitus (T1DM) and GFR $\leq 60 \mathrm{~mL}$ / $\mathrm{min} / 1.73 \mathrm{~m}^{2}$ (with or without albuminuria), the differences in the clinical features associated with the two different chronic kidney disease phenotypes and we investigated, in a subset of patients, the modulating role of albuminuria on kidney disease progression.

Methods: Clinical data of 1395 patients with T1DM were extracted from electronic medical records.

Results: Albuminuria was detected in 676 (48.5\%) patients, with the remaining 719 (51.5\%) patients having normoalbuminuric renal impairment. Those with albuminuria showed an evident worse cardiovascular risk profile as compared to patients with normoalbuminuria. A subgroup of 582 patients was followed up over a 4-year period. One hundred and twenty five patients (21.5\%) showed a loss of eGFR $>30 \%$. The proportion of patients reaching the renal outcome was significantly higher among those with baseline albuminuria as compared to patients with normoalbuminuria $(P<0.0001)$. At the multivariate logistic analysis microalbuminuria, macroalbuminuria and proliferative retinopathy were the only parameters independently associated to eGFR reduction.
\end{abstract}

Conclusions: The proportion of T1DM patients with normoalbuminuria renal impairment is high (about 50\%). These patients have a slower eGFR decline as compared to that observed in patients with albuminuria renal impairment.

Keywords: Albuminuria, Chronic kidney disease, Type 1 diabetes mellitus, Cardiovascular disease

\section{Background}

Diabetic kidney disease (DKD), an important complication of diabetes mellitus, is the leading cause of kidney failure in the western word and it is also associated with increased cardiovascular morbidity and mortality. Albuminuria and reduced glomerular filtration rate (GFR) are the key features of DKD. Traditionally, the earliest clinical manifestation of DKD has been the detection of persistent microalbuminuria [1]. Early studies suggested that GFR starts to decrease only when albuminuria

\footnotetext{
*Correspondence: olga.lamacchia@unifg.it; sdecosm@tin.it

${ }^{1}$ Unit of Endocrinology and Metabolic Diseases, Department of Surgical

and Medical Sciences, University of Foggia, Foggia, Italy

${ }^{4}$ Department of Medical Sciences, Scientific Institute "Casa Sollievo della

Sofferenza", San Giovanni Rotondo, FG, Italy

Full list of author information is available at the end of the article
}

reaches the macroalbuminuric range [2]. This conventional paradigm of kidney disease in people with diabetes has been recently challenged. Changes in albuminuria and GFR are being increasingly recognized as complementary rather than obligatory manifestations of DKD. Furthermore, albuminuria and loss of GFR seem to be associated with distinct clusters of specific risk factors. Several studies investigating the prevalence of both normoalbuminuric and albuminuric chronic kidney disease (CKD) have been performed in type 2 diabetes mellitus (T2DM) [3-7]. Limited information is available concerning heterogeneity of renal features in patients with type 1 diabetes mellitus (T1DM) and this is largely resulting from studies conducted in a few cohorts of patients with GFR $\leq 60 \mathrm{~mL} / \mathrm{min} / 1.73 \mathrm{~m}^{2}$ [8-10]. Recently, Penno et al. [10] have recently assessed the prevalence and 
correlates of different CKD phenotypes in a cohort of 777 patients with T1DM (of which 29 with eGFR $<60 \mathrm{~mL} /$ $\mathrm{min} / 1.73 \mathrm{~m}^{2}$ ). They found that normoalbuminuric CKD phenotype is present in a significant proportion of the T1DM, a finding supporting two distinct pathways, with and without albuminuria, to advanced kidney disease.

We therefore analyzed a large sample of patients with T1DM and GFR $\leq 60 \mathrm{~mL} / \mathrm{min} / 1.73 \mathrm{~m}^{2}$ (with or without albuminuria) attending diabetes clinics and representative of current clinical practice for diabetes care in Italy to describe the differences in the clinical features associated with the two different CKD phenotypes (i.e. with and without albuminuria) and to investigate, in a subset of patients, the modulating role of albuminuria on kidney disease progression.

\section{Methods}

In this report, we show the results of an analysis performed using the data set of the electronic medical records collected on a large sample of patients with a diagnosis of T1DM (according to American Diabetes Association 2003 criteria), who attended 295 diabetes clinics in Italy between 1 January 2004, and 31 December 2011. Approximately, one-third of all the Italian diabetes clinics were involved in this study, evenly distributed throughout the country and therefore indicative of the clinical practice. For the purpose of the analysis, we considered only patients who were aged 18 years or older, with at least 1 outpatient measurement of serum creatinine and albuminuria and with a GFR $\leq 60 \mathrm{~mL} /$ $\min / 1.73 \mathrm{~m}^{2}$. A total of 1395 patients (654 males and 741 females) constituted the study population (Additional file 1: Fig. S1).

The database derives from the Italian Association of Clinical Diabetologists (Associazione Medici Diabetologi-AMD) initiative designed to monitor diabetes care and quality of care as previously reported [11-13]. All participating clinics used an electronic clinical record system, and a software specifically developed to extract information. Data from all participating clinics were collected anonymously and were centrally analyzed [11-13]. The results were internally approved by the AMD Annals scientific committee. The core data-set included measures and monitoring of glycated hemoglobin (HbA1c), total cholesterol, low-density lipoprotein cholesterol (LDL-c) or high density lipoprotein cholesterol (HDL-c), and triglycerides. The use of specific classes of drugs was also evaluated. Kidney function was assessed by serum creatinine, measured by modified Jaffè method, and urinary albumin excretion measurements (UAE). Glomerular filtration rate (GFR) was estimated for each patient by using the CKD epidemiology collaboration formula derived by serum creatinine values [14]. Increased UAE was diagnosed as (1) microalbuminuria if urinary albumin concentration was $>30$ and $\leq 300 \mathrm{mg} / \mathrm{L}$, or if UAE rate was $>20$ and $\leq 200 \mu \mathrm{g} / \mathrm{min}$, or if urinary albumin-tocreatinine ratio was $>2.5 \mathrm{mg} / \mathrm{mmol}$ in men and $>3.5 \mathrm{mg} /$ $\mathrm{mmol}$ in women and $\leq 30 \mathrm{mg} / \mathrm{mmol}$ in both gender and (2) macroalbuminuria if urinary albumin concentration was $>300 \mathrm{mg} / \mathrm{L}$, or if UAE rate was $>200 \mu \mathrm{g} / \mathrm{min}$, or if albumin-to-creatinine ratio was $>30 \mathrm{mg} / \mathrm{mmol}$ in both gender. Urine albumin excretion was evaluated by means of urine albumin concentration in the majority of study patients 1020 (i.e. 73\%) and by albumin to creatinine ratio (spot morning samples) in a smaller number of patients 344 (25\%). Timed urine collection $(24 \mathrm{~h})$ was used in a minority of patients 31 (2\%).

Albuminuria indicates patients with either microalbuminuria or macroalbuminuria. DKD was defined as diabetes with albuminuria and/or low GFR $(\leq 60 \mathrm{~mL} /$ $\mathrm{min} / 1.73 \mathrm{~m}^{2}$ ). Information on the presence of diabetic retinopathy, background (BR), or proliferative (PR), was also available. At each participating center, all patients underwent physical examination and blood pressure (BP) measurements according to a standardized protocol. BP was measured with the patient in the sitting position after a 5-min rest, with a mercury sphygmomanometer.

For the cross-sectional analyses, we extracted data from the most recent patients' visit complete of eGFR measurement and albuminuria evaluation. To obtain the 4-year evaluations, we selected for each patient the last 4-year period that included eGFR and albuminuria status at baseline and a re-evaluation of eGFR 4 years later. As a consequence of selection criteria, the baseline included a visit up to the year 2008 and the follow-up up to 2011 (range of visits $48 \pm 6$ months selecting that closest to 48 month). For patients without a re-evaluation at 4-year, the last visit up to the year 2008 was considered for the cross-sectional study (the same period of baseline visit for the longitudinal population).

\section{Statistical analysis}

Data are given as mean value \pm standard deviation or median (interquartile range), and categorical variables are described as frequencies and percentages. Logistic regression analysis was used to evaluate variables associated to albuminuria. Predictors of eGFR reduction $>30 \%$ [15] than baseline were evaluated with a logistic model adjusting for baseline eGFR. A multivariate model was built selecting variables associated to the outcome with a $\mathrm{P}$ value $<0.05$ adjusting for age and gender. Multivariate analysis was performed as complete-case analysis including patients with all data available. The odds ratios (ORs) were used to estimate the degree of association with outcome. Assuming linearity of eGFR reduction over time, its slope was 
taken as a measure of disease progression rate. For each patients, we calculated the regression coefficient (slope) of linear regression between eGFR value and the exact time in years from the first evaluation including all measurements from baseline to the 4-year visit. The analyses were made using STATA software, Version 14 (StataCorp, College Station, TX). P values of $<0.05$ were considered statistically significant.

\section{Results}

The main clinical features of the study population $(n=1395)$ at baseline, as a whole and grouped by the presence/absence of albuminuria, are summarized in Table 1 . Overall, the mean age of patients was $63 \pm 14$ years, $46.9 \%$ were male and mean duration of diabetes was $27 \pm 14$ years. Taking into account the presence of CKD, glycemic and blood pressure controls were fairly good. A total of 986 (70.7\%) and $611(43.8 \%)$

Table 1 Baseline clinical characteristics of 1395 T1DM patients with low eGFR as whole and after stratification by the presence of albuminuria

\begin{tabular}{|c|c|c|c|c|}
\hline & $\begin{array}{l}\text { Overall } \\
n=1395\end{array}$ & $\begin{array}{l}\text { Normoalbuminuria } \\
\mathrm{n}=719\end{array}$ & $\begin{array}{l}\text { Albuminuria } \\
n=676\end{array}$ & $\mathbf{P}$ \\
\hline Male sex & $654(46.9 \%)$ & $252(35.0 \%)$ & $402(59.5 \%)$ & $<0.001$ \\
\hline Age (years) & $63 \pm 14$ & $66 \pm 12$ & $60 \pm 14$ & $<0.001$ \\
\hline Duration of diabetes (years) & $27 \pm 14$ & $27 \pm 15$ & $27 \pm 13$ & 0.968 \\
\hline $\mathrm{BMI}\left(\mathrm{kg} / \mathrm{m}^{2}\right)$ & $26.3 \pm 4.7$ & $26.2 \pm 4.5$ & $26.5 \pm 4.9$ & 0.201 \\
\hline Serum creatinine (mg/dL) & $1.55 \pm 0.81$ & $1.35 \pm 0.52$ & $1.78 \pm 0.98$ & $<0.001$ \\
\hline $\mathrm{eGFR}\left(\mathrm{mL} / \mathrm{min} / 1.73 \mathrm{~m}^{2}\right)$ & $46 \pm 12$ & $49 \pm 10$ & $43 \pm 13$ & $<0.001$ \\
\hline Albuminuria & $676(48.5 \%)$ & - & - & \\
\hline Serum uric acid (mg/dL) & $5.7 \pm 1.8$ & $5.3 \pm 1.8$ & $6.1 \pm 1.6$ & $<0.001$ \\
\hline Serum uric acid in the top quintile & $162(19.0 \%)$ & $60(14.3 \%)$ & $102(23.5 \%)$ & 0.001 \\
\hline HbA1c (\%) & $8.2 \pm 1.6$ & $8.0 \pm 1.5$ & $8.3 \pm 1.7$ & $<0.001$ \\
\hline $\mathrm{HbA} 1 \mathrm{c}(\mathrm{mmol} / \mathrm{mol})$ & $66 \pm 17.5$ & $64.0 \pm 16.4$ & $67 \pm 18.6$ & $<0.001$ \\
\hline $\mathrm{HbA} 1 \mathrm{c} \geq 7 \%$ & $1071(77.4 \%)$ & $541(75.7 \%)$ & $530(79.2 \%)$ & 0.114 \\
\hline $\mathrm{HbA} 1 \mathrm{c} \geq 54 \mathrm{mmol} / \mathrm{mol}$ & $1071(77.4 \%)$ & $541(75.7 \%)$ & $530(79.2 \%)$ & 0.114 \\
\hline Total cholesterol (mg/dL) & $195 \pm 44$ & $192 \pm 38$ & $198 \pm 48$ & 0.012 \\
\hline Triglycerides (mg/dL) & $122 \pm 82$ & $110 \pm 74$ & $136 \pm 89$ & $<0.001$ \\
\hline Triglycerides $\geq 150 \mathrm{mg} / \mathrm{dL}$ & $292(22.4 \%)$ & $113(16.8 \%)$ & $179(28.5 \%)$ & $<0.001$ \\
\hline $\mathrm{HDL}(\mathrm{mg} / \mathrm{dL})$ & $60 \pm 19$ & $61 \pm 19$ & $58 \pm 20$ & 0.008 \\
\hline $\mathrm{HDL}<40 \mathrm{M}<50 \mathrm{~F} \mathrm{mg} / \mathrm{dL}$ & $269(20.8 \%)$ & $133(20.0 \%)$ & $136(21.6 \%)$ & 0.491 \\
\hline LDL (mg/dL) & $112 \pm 35$ & $109 \pm 32$ & $114 \pm 38$ & 0.027 \\
\hline $\mathrm{LDL} \geq 100 \mathrm{mg} / \mathrm{dL}$ & $785(61.1 \%)$ & $402(60.4 \%)$ & $383(61.9 \%)$ & 0.578 \\
\hline Systolic BP (mmHg) & $139 \pm 20$ & $137 \pm 20$ & $141 \pm 20$ & $<0.001$ \\
\hline Diastolic BP (mmHg) & $77 \pm 10$ & $76 \pm 10$ & $78 \pm 10$ & 0.006 \\
\hline Blood pressure $\geq 140 / 85 \mathrm{mmHg}$ & $659(57.8 \%)$ & $315(53.9 \%)$ & $344(61.9 \%)$ & 0.007 \\
\hline Non-proliferative retinopathy & $279(20.0 \%)$ & $152(21.1 \%)$ & $127(18.8 \%)$ & 0.272 \\
\hline Proliferative retinopathy & $146(10.5 \%)$ & $56(7.8 \%)$ & $90(13.3 \%)$ & 0.001 \\
\hline Smokers & 107 (18.7\%) & $40(13.5 \%)$ & $67(24.3 \%)$ & 0.001 \\
\hline Lipid-lowering treatment & $611(43.8 \%)$ & $301(41.9 \%)$ & $310(45.9 \%)$ & 0.133 \\
\hline Treatment with statins & $579(41.5 \%)$ & $287(39.9 \%)$ & $292(43.2 \%)$ & 0.214 \\
\hline Treatment with fibrates & $14(1.0 \%)$ & $9(1.3 \%)$ & $5(0.7 \%)$ & 0.343 \\
\hline Antihypertensive treatment & $986(70.7 \%)$ & $453(63.0 \%)$ & $533(78.8 \%)$ & $<0.001$ \\
\hline Treatment with ACE-Is/ARBs & $862(61.8 \%)$ & $384(53.4 \%)$ & $478(70.7 \%)$ & $<0.001$ \\
\hline Aspirin & $339(24.3 \%)$ & $158(22.0 \%)$ & $181(26.8 \%)$ & 0.037 \\
\hline Insulin pump & $52(3.7 \%)$ & $17(2.4 \%)$ & $35(5.2 \%)$ & 0.007 \\
\hline
\end{tabular}

Mean \pm SD or absolute frequency (percentage). Patients' baseline missing data: duration of diabetes 72 (5.2\%), BMI 212 (15.2\%), serum uric acid 542 (38.9\%), HbA1c 11 (0.8\%), total cholesterol $73(5.2 \%)$, triglycerides $92(6.6 \%)$, HDL $99(7.1 \%)$, LDL $110(7.9 \%)$, blood pressure 255 (18.3\%), smokers 823 (59.0\%). Serum uric acid in the top gender-specific quintile: $>6.6 \mathrm{mg} / \mathrm{dL}$ in females and $>7.4 \mathrm{mg} / \mathrm{dL}$ in males

eGFR estimated glomerular filtration rate, $B M I$ body mass index, $H b A 1 c$ glycated haemoglobin, $H D L$ high-density lipoprotein cholesterol, $L D L$ low-density lipoprotein cholesterol, $A C E-I s$ angiotensin converting enzyme-inhibitors, ARBs angiotensin II receptor antagonists 
patients were on antihypertensive and on lipid-lowering treatment, respectively. In our sample, albuminuria was detected in 676 (48.5\%) patients, with the remaining 719 (51.5\%) patients having normoalbuminuric renal impairment (Table 1). Those with albuminuria were more likely to be males and, on average, younger respect to patients without albuminuria. Duration of disease was comparable between patients with or without albuminuria. Albuminuria was also associated with a worse glycemic control and higher levels of serum uric acid. Furthermore, albuminuria was associated with a more atherogenic lipid profile (i.e. higher LDL cholesterol and triglycerides levels and lower HDL-c) and higher values of systolic BP (SBP) and diastolic BP (DBP) despite a greater prevalence of antidyslipidemic and antihypertensive treatment.

As expected, individuals with albuminuria were more frequently treated with angiotensin converting enzyme inhibitors (ACE-Is) or angiotensin II receptor antagonists (ARBs) as compared to those without albuminuria. Moreover, they were more likely to be smokers and to show proliferative retinopathy.

We have also compared clinical features of patients with micro or macroalbuminuria. Those with macroalbuminuria showed an evident worse cardiovascular (CV) risk profile as compared to patients with microalbuminuria (Additional file 2: Table S1).

To investigate the differences in the kidney dysfunction progression between patients with low eGFR and normoalbuminuria or albuminuria, a subgroup of 582 patients, whose clinical features are showed in Table 2 and Additional file 2: Table S2, was followed up over a 4-year period. One hundred and twenty five patients (21.5\%) showed a loss of eGFR $>30 \%$. The proportion of patients reaching the renal outcome was significantly higher among those with baseline albuminuria as compared to patients with normoalbuminuria $(33.6 \%$ vs $10.5 \%$, albuminuria vs normoalbuminuria, respectively $\mathrm{P}<0.0001)$. The slope of GFR decline was of $-0.5(-2.2$; 1.5) $\mathrm{mL} / \mathrm{min} / 1.73 \mathrm{~m}^{2} /$ year for the whole sample. Patients with normoalbuminuria showed a stable kidney function along the follow-up period [i.e. $+0.4(-1.2 ; 3.2) \mathrm{mL} /$ $\min / 1.73 \mathrm{~m}^{2} /$ year] while those with albuminuria had a significant progression of kidney disease $[-1.3(-3.2$; $0.3) \mathrm{mL} / \mathrm{min} / 1.73 \mathrm{~m}^{2} /$ year]. The main baseline clinical features of the above study population grouped by renal outcome at 4-year follow-up are summarized in Table 3. Patients who went on to develop renal outcome showed a poor glycemic control and higher levels of triglycerides and serum uric acid as compared to patients who did not. Furthermore, they had higher levels of SBP despite a greater prevalence of antihypertensive treatment.
As expected, they had also a lower eGFR at baseline (43 vs. $48 \mathrm{~mL} / \mathrm{min} / 1.73 \mathrm{~m}^{2}, \mathrm{P}<0.001$ ).

Almost 2/3 of patients who went on to develop eGFR reduction $>30 \%$ showed albuminuria at baseline and $19 \%$ showed proliferative retinopathy. At the multivariate logistic analysis microalbuminuria, macroalbuminuria and proliferative retinopathy were the only parameters independently associated to eGFR reduction (Table 4).

\section{Discussion}

In a large cohort representative of real life clinical practice in Italy, we found that up to $50 \%$ of patients with T1DM and CKD show a non albuminuric phenotype. In addition, we demonstrate that the loss of GFR is much greater in T1DM albuminuric CKD as compared with T1DM normoalbuminuric CKD patients.

The prevalence of normoalbuminuric CKD in our population was higher than that in the Finnish Diabetic Nephropathy Study [16] where, of the 502 patients with CKD, 78 (16\%) did not have albuminuria. This difference could likely be accounted for by differences in patients' clinical features and in setting were the patients have been studied. A cross-sectional survey of the UK National Diabetes Audit [9] investigating a large cohort of T1DM patients has recently reported the presence of normoalbuminuria in $54.4 \%$ of individuals stage $\geq 3$ CKD, a proportion similar to our finding. In a very recent retrospective study by Penno et al. [10], the authors found that, among 29 patients with eGFR $<60 \mathrm{~mL} / \mathrm{min} / 1.73 \mathrm{~m}^{2}$, $17(58.6 \%)$ had normoalbuminuria. The authors couldn't find any significant differences for most of clinical variables investigated, very likely because of the small number of patients evaluated. Furthermore, the study conducted by Penno et al. was a cross-sectional, single-centre study while in our study the patients were recruited from more than 200 diabetes clinics in Italy distributed throughout the country and therefore indicative of the clinical practice in the real life condition. The pathophysiology and clinical significance of low GFR levels in patients without albuminuria is to this day unclear. While in patients with T2DM the occurrence of non albuminuric renal impairment has been related to pathogenetic mechanisms such as premature kidney senescence, interstitial fibrosis, ischaemic vascular disease or cholesterol microemboli [3] which may differ from those involved in the development of traditional diabetic glomerulosclerosis, it is currently uncertain whether a similar pathogenetic scenario also applies to T1DM patients with non albuminuric renal dysfunction. Glomerular structural changes typical of diabetic nephropathy, have been reported in T1DM 
Table 2 Baseline clinical characteristics of 582 type 1 diabetes mellitus patients with low eGFR and with 4 year follow-up, overall and on the basis of albuminuria

\begin{tabular}{|c|c|c|c|c|}
\hline & $\begin{array}{l}\text { Overall } \\
n=582\end{array}$ & $\begin{array}{l}\text { Normoalbuminuria } \\
\mathrm{n}=305\end{array}$ & $\begin{array}{l}\text { Albuminuria } \\
n=277\end{array}$ & $P$ \\
\hline Male sex & $262(45.0 \%)$ & $99(32.5 \%)$ & $163(58.8 \%)$ & $<0.001$ \\
\hline Age (years) & $63 \pm 13$ & $65 \pm 12$ & $60 \pm 13$ & $<0.001$ \\
\hline Duration of diabetes (years) & $27 \pm 13$ & $26 \pm 14$ & $27 \pm 12$ & 0.385 \\
\hline BMI $\left(\mathrm{kg} / \mathrm{m}^{2}\right)$ & $27 \pm 5$ & $26 \pm 4$ & $27 \pm 6$ & 0.085 \\
\hline Serum creatinine $(\mathrm{mg} / \mathrm{dL})$ & $1.55 \pm 0.90$ & $1.31 \pm 0.40$ & $1.81 \pm 1.19$ & $<0.001$ \\
\hline $\mathrm{eGFR}\left(\mathrm{mL} / \mathrm{min} / 1.73 \mathrm{~m}^{2}\right)$ & $47 \pm 12$ & $50 \pm 10$ & $43 \pm 13$ & $<0.001$ \\
\hline $\operatorname{eGFR}\left(\mathrm{mL} / \mathrm{min} / 1.73 \mathrm{~m}^{2}\right)$ & $50(39-56)$ & $52(45-57)$ & $46(35-54)$ & $<0.001$ \\
\hline Serum uric acid (mg/dL) & $5.6 \pm 1.6$ & $5.1 \pm 1.4$ & $6.1 \pm 1.6$ & $<0.001$ \\
\hline Serum uric acid in the top quintile & $65(18.2 \%)$ & $20(11.4 \%)$ & $45(24.7 \%)$ & 0.001 \\
\hline $\mathrm{HbA1c}(\%)$ & $8.1 \pm 1.5$ & $8.0 \pm 1.3$ & $8.3 \pm 1.6$ & 0.036 \\
\hline $\mathrm{HbA1c}(\mathrm{mmol} / \mathrm{mol})$ & $65 \pm 16.4$ & $64 \pm 14.2$ & $67 \pm 17.5$ & 0.036 \\
\hline $\mathrm{HbA} 1 \mathrm{c} \geq 7 \%$ & $453(78.5 \%)$ & $234(77.2 \%)$ & $219(79.9 \%)$ & 0.431 \\
\hline $\mathrm{HbA} 1 \mathrm{c} \geq 54 \mathrm{mmol} / \mathrm{mol}$ & $453(78.5 \%)$ & $234(77.2 \%)$ & $219(79.9 \%)$ & 0.431 \\
\hline Total cholesterol (mg/dL) & $196 \pm 40$ & $197 \pm 37$ & $195 \pm 43$ & 0.677 \\
\hline Triglycerides (mg/dL) & $121 \pm 81$ & $110 \pm 82$ & $133 \pm 79$ & 0.002 \\
\hline Triglycerides $\geq 150 \mathrm{mg} / \mathrm{dL}$ & $118(22.1 \%)$ & $46(16.6 \%)$ & $72(28.0 \%)$ & 0.002 \\
\hline $\mathrm{HDL}(\mathrm{mg} / \mathrm{dL})$ & $59 \pm 19$ & $62 \pm 19$ & $57 \pm 18$ & 0.004 \\
\hline $\mathrm{HDL}<40 \mathrm{M}<50 \mathrm{~F} \mathrm{mg} / \mathrm{dL}$ & 105 (19.7\%) & $54(19.5 \%)$ & $51(20.0 \%)$ & 0.884 \\
\hline $\mathrm{LDL}(\mathrm{mg} / \mathrm{dL})$ & $113 \pm 33$ & $113 \pm 31$ & $112 \pm 35$ & 0.636 \\
\hline $\mathrm{LDL} \geq 100 \mathrm{mg} / \mathrm{dL}$ & $349(66.0 \%)$ & $188(68.1 \%)$ & $161(63.6 \%)$ & 0.278 \\
\hline Systolic BP (mmHg) & $139 \pm 19$ & $137 \pm 19$ & $141 \pm 19$ & 0.032 \\
\hline Diastolic BP (mmHg) & $77 \pm 9$ & $77 \pm 9$ & $78 \pm 10$ & 0.204 \\
\hline Blood pressure $\geq 140 / 85 \mathrm{mmHg}$ & $276(59.2 \%)$ & $138(56.1 \%)$ & $138(62.7 \%)$ & 0.146 \\
\hline Non-proliferative retinopathy & $123(21.1 \%)$ & $64(21.0 \%)$ & $59(21.3 \%)$ & 0.926 \\
\hline Proliferative retinopathy & $68(11.7 \%)$ & $24(7.9 \%)$ & $44(15.9 \%)$ & 0.003 \\
\hline Smokers & $46(18.8 \%)$ & $20(14.5 \%)$ & $26(24.3 \%)$ & 0.053 \\
\hline Lipid-lowering treatment & $253(43.5 \%)$ & $124(40.7 \%)$ & $129(46.6 \%)$ & 0.151 \\
\hline Treatment with statins & $238(40.9 \%)$ & $115(37.7 \%)$ & $123(44.4 \%)$ & 0.101 \\
\hline Treatment with fibrates & $8(1.4 \%)$ & $5(1.6 \%)$ & $3(1.1 \%)$ & 0.568 \\
\hline Antihypertensive treatment & $421(72.3 \%)$ & $199(65.2 \%)$ & $222(80.1 \%)$ & $<0.001$ \\
\hline Treatment with ACE-Is/ARBs & $372(63.9 \%)$ & $171(56.1 \%)$ & $201(72.6 \%)$ & $<0.001$ \\
\hline Aspirin & $139(23.9 \%)$ & $67(22.0 \%)$ & $72(26.0 \%)$ & 0.256 \\
\hline Insulin pump & $18(3.1 \%)$ & $2(0.7 \%)$ & $16(5.8 \%)$ & 0.003 \\
\hline 4-year eGFR reduction > 30\% & $125(21.5 \%)$ & $32(10.5 \%)$ & $93(33.6 \%)$ & $<0.001$ \\
\hline eGFR at follow-up (mL/min/1.73 m²) & $47(33-58)$ & $53(41-66)$ & $38(25-49)$ & $<0.001$ \\
\hline
\end{tabular}

Mean \pm SD, median (interquartile range) or absolute frequency (percentage). Patients' baseline missing data: duration of diabetes 18 (3.1\%), BMI 108 (18.6\%), serum uric acid $225(38.7 \%)$, HbA1c $5(0.9 \%)$, total cholesterol 41 (7.0\%), triglycerides $48(8.2 \%)$, HDL 50 (8.6\%), LDL 53 (9.1\%), blood pressure 116 (19.9\%), smokers 337 $(57.9 \%)$

eGFR estimated glomerular filtration rate, BMI body mass index, HbA1c glycated haemoglobin, HDL high-density lipoprotein cholesterol, $L D L$ low-density lipoprotein cholesterol, ACE-Is angiotensin converting enzyme-inhibitors, ARBs angiotensin II receptor antagonists 
Table 3 Baseline clinical characteristics of 582 type 1 diabetes mellitus patients reaching the renal end-point (estimated Glomerular filtration rate reduction $>\mathbf{3 0} \%$ )

\begin{tabular}{|c|c|c|c|}
\hline & \multicolumn{2}{|c|}{$\begin{array}{l}\text { 4-year eGFR } \\
\text { reduction }>30 \%\end{array}$} & \multirow[t]{2}{*}{$\mathbf{P}$} \\
\hline & $\begin{array}{l}\text { No } \\
n=457\end{array}$ & $\begin{array}{l}\text { Yes } \\
n=125\end{array}$ & \\
\hline Male sex & $197(43.1 \%)$ & $65(52.0 \%)$ & 0.149 \\
\hline Age (years) & $63 \pm 13$ & $61 \pm 14$ & 0.295 \\
\hline Known duration of diabetes (years) & $27 \pm 13$ & $27 \pm 13$ & 0.726 \\
\hline BMI $\left(\mathrm{kg} / \mathrm{m}^{2}\right)$ & $26 \pm 5$ & $27 \pm 6$ & 0.277 \\
\hline Serum creatinine (mg/dL) & $1.49 \pm 0.86$ & $1.75 \pm 1.02$ & 0.501 \\
\hline $\mathrm{eGFR}\left(\mathrm{mL} / \mathrm{min} / 1.73 \mathrm{~m}^{2}\right)$ & $48 \pm 11$ & $43 \pm 13$ & $<0.001$ \\
\hline Albuminuria & $184(40.3 \%)$ & $93(74.4 \%)$ & $<0.001$ \\
\hline Microalbuminuria & $131(28.7 \%)$ & $41(32.8 \%)$ & 0.001 \\
\hline Macroalbuminuria & $53(11.6 \%)$ & $52(41.6 \%)$ & $<0.001$ \\
\hline Serum uric acid (mg/dL) & $5.4 \pm 1.5$ & $6.2 \pm 1.8$ & 0.004 \\
\hline $\begin{array}{l}\text { Serum uric acid in the top gender- } \\
\text { specific quintile }\end{array}$ & $40(14.5 \%)$ & $25(30.9 \%)$ & 0.038 \\
\hline $\mathrm{HbA1c}(\%)$ & $8.1 \pm 1.4$ & $8.4 \pm 1.5$ & 0.049 \\
\hline $\mathrm{HbA1c}(\mathrm{mmol} / \mathrm{mol})$ & $65 \pm 15.3$ & $68 \pm 16.4$ & 0.049 \\
\hline $\mathrm{HbA} 1 \mathrm{c} \geq 7 \%$ & $350(77.3 \%)$ & $103(83.1 \%)$ & 0.129 \\
\hline $\mathrm{HbA} 1 \mathrm{c} \geq 53 \mathrm{mmol} / \mathrm{mol}$ & $350(77.3 \%)$ & $103(83.1 \%)$ & 0.129 \\
\hline Total cholesterol (mg/dL) & $196 \pm 38$ & $196 \pm 48$ & 0.912 \\
\hline Triglycerides (mg/dL) & $114 \pm 63$ & $147 \pm 125$ & 0.003 \\
\hline Triglycerides $\geq 150 \mathrm{mg} / \mathrm{dL}$ & $84(19.9 \%)$ & $34(30.4 \%)$ & 0.054 \\
\hline $\mathrm{HDL}(\mathrm{mg} / \mathrm{dL})$ & $60 \pm 19$ & $56 \pm 18$ & 0.086 \\
\hline $\mathrm{HDL}<40 \mathrm{M}<50 \mathrm{~F} \mathrm{mg} / \mathrm{dL}$ & $81(19.2 \%)$ & $24(21.8 \%)$ & 0.791 \\
\hline LDL (mg/dL) & $113 \pm 30$ & $112 \pm 42$ & 0.964 \\
\hline $\mathrm{LDL} \geq 100 \mathrm{mg} / \mathrm{dL}$ & $280(66.8 \%)$ & $69(62.7 \%)$ & 0.585 \\
\hline Systolic BP (mmHg) & $138 \pm 19$ & $143 \pm 20$ & 0.040 \\
\hline Diastolic BP (mmHg) & $77 \pm 9$ & $78 \pm 10$ & 0.128 \\
\hline $\mathrm{BP} \geq 140 / 85 \mathrm{mmHg}$ & $208(57.3 \%)$ & $68(66.0 \%)$ & 0.092 \\
\hline Non-proliferative retinopathy & $99(21.7 \%)$ & $24(19.2 \%)$ & 0.850 \\
\hline Proliferative retinopathy & $44(9.6 \%)$ & $24(19.2 \%)$ & 0.008 \\
\hline Smokers & $32(16.8 \%)$ & $14(25.9 \%)$ & 0.060 \\
\hline Lipid-lowering treatment & $193(42.2 \%)$ & $60(48.0 \%)$ & 0.302 \\
\hline Treatment with statins & $184(40.3 \%)$ & $54(43.2 \%)$ & 0.589 \\
\hline Treatment with fibrates & $5(1.1 \%)$ & $3(2.4 \%)$ & 0.308 \\
\hline Antihypertensive treatment & $317(69.4 \%)$ & $104(83.2 \%)$ & 0.010 \\
\hline Treatment with ACE-Is/ARBs & $284(62.1 \%)$ & $88(70.4 \%)$ & 0.226 \\
\hline Aspirin & $107(23.4 \%)$ & $32(25.6 \%)$ & 0.715 \\
\hline Insulin pump & $10(2.2 \%)$ & $8(6.4 \%)$ & 0.050 \\
\hline
\end{tabular}

Mean \pm SD or absolute frequency (percentage). Patients' baseline missing data: duration of diabetes $18(3.1 \%)$, BMl $108(18.6 \%)$, serum uric acid $225(38.7 \%)$, HbA1c 5 (0.9\%), total cholesterol 41 (7.0\%), triglycerides $48(8.2 \%)$, HDL 50 (8.6\%), LDL 53 (9.1\%), blood pressure 116 (19.9\%), smokers 337 (57.9\%)

eGFR estimated glomerular filtration rate, $B M I$ body mass index, HbA1C glycated haemoglobin, $H D L$ high-density lipoprotein cholesterol, $L D L$ low-density lipoprotein cholesterol, ACE-Is angiotensin converting enzyme-inhibitors, ARBs angiotensin II receptor antagonists

The $P$ value refers to the effect of each variable on 4-year eGFR reduction $>30 \%$ at logistic regression analysis adjusted for baseline eGFR patients with normoalbuminuria and reduced GFR [17]. In these patients, a thickening of the glomerular basal membrane and a greater fractional volume of the glomerulus occupied by mesangium have been found as compared with those who had a normal GFR. Probably the expression of some proteins, such as nephrin, responsible of the integrity of the slit diaphragm, remains unchanged in patients with normoalbuminuric renal insufficiency [18].

When we focused on differences in the kidney dysfunction progression we found that the loss of GFR was greater in albuminuric CKD patients as compared to normoalbuminuric CKD patients. Patients with normoalbuminuria showed a stable kidney function along the follow-up period while those with albuminuria had a significant progression of kidney disease. This finding is in line with the results of Holfiel et al. who described the accelerating effect of albuminuria in the loss of GFR in patients with T1DM and T2DM [19]. Normoalbuminuric renal impairment is a widely described strong risk factor for cardiovascular mortality and morbidity in the general population and in patients with T2DM [20]. Data on this specific issue in patients with T1DM are lacking.

Our study has several limitations as well as strengths. First of all, laboratory variables were not centralized and this could have caused variability especially in the creatinine assay. However, most laboratories around the country currently use the modified Jaffè method, which has good reproducibility. In addition, we have classified our patients using only one measurement of albuminuria. This is in line with other studies [21, 22]. Pugliese et al. [21] have recently reported in a large cohort of subjects with T2DM participating in the renal insufficiency and cardiovascular events (RIACE) Italian Multicentre Study, that a single UAE value, thought to be encumbered with high intra-individual variability, is an accurate predictor of nephropathy stage for clinical and epidemiological purposes. On the other hand, the large number of patients studied and the consistent geographical distribution of the recruiting centers are major strengths of the study, which gives missing information about this issue in Italy. Further limitations merit to be mentioned, i.e. lack of information on: (i) previous cardiovascular events, cancer, infection and hospitalization during the followup period, (ii) historical albuminuria data and (iii) duration of smoking habit.

In conclusion, our study shows as the proportion of T1DM patients with normoalbuminuria renal impairment is high (about 50\%). These patients have a slower eGFR decline as compared to that observed in patients with albuminuria renal impairment. Whether T1DM patients with albuminuric renal impairment 
Table 4 Baseline predictors at multivariate analysis for 4-year eGFR reduction > $30 \%$

\begin{tabular}{|c|c|c|c|c|}
\hline & Odds ratio & $\mathbf{P}$ & Odds ratio & $\mathbf{P}$ \\
\hline Male sex & $0.95(0.55-1.65)$ & 0.861 & $0.87(0.49-1.53)$ & 0.620 \\
\hline Age (by 10 years) & $0.90(0.73-1.11)$ & 0.331 & $0.95(0.76-1.18)$ & 0.615 \\
\hline eGFR (by 10 mL/min/1.73 m²) & $0.86(0.70-1.06)$ & 0.164 & $0.89(0.72-1.11)$ & 0.303 \\
\hline Albuminuria & $4.09(2.22-7.56)$ & $<0.001$ & - & \\
\hline Microalbuminuria & - & & $2.50(1.26-4.95)$ & 0.009 \\
\hline Macroalbuminuria & - & & $9.25(4.44-19.25)$ & $<0.001$ \\
\hline $\mathrm{HbA1c}$ (by 1\%) & $1.10(0.92-1.31)$ & 0.299 & $1.06(0.88-1.27)$ & 0.559 \\
\hline Triglycerides (by 10 mg/dL) & $1.02(0.99-1.05)$ & 0.237 & $1.02(0.99-1.06)$ & 0.248 \\
\hline Systolic blood pressure (by 10 mmHg) & $1.11(0.97-1.27)$ & 0.145 & $1.09(0.95-1.25)$ & 0.232 \\
\hline Proliferative retinopathy & $2.39(1.22-4.68)$ & 0.011 & $2.36(1.18-4.73)$ & 0.016 \\
\hline Antihypertensive treatment & $2.19(0.97-4.92)$ & 0.059 & $2.14(0.93-4.92)$ & 0.074 \\
\hline
\end{tabular}

Complete case analysis performed by using a logistic regression model including 427 patients (91 with eGFR reduction $>30 \%$ ) for which all data were observed eGFR estimated glomerular filtration rate, $\mathrm{HbA1c}$ glycated haemoglobin

as compared to patients with normoalbuminuric renal impairment need a more intensive renal protection treatment will be clarified by further intervention studies.

\section{Additional files}

Additional file 1: Fig. S1. Flow-chart of population.

Additional file 2: Table S1. Baseline clinical characteristics of 676 patients with T1DM with low eGFR on the basis of micro- and macro-albuminuria. Table S2. Baseline clinical characteristics of 277 patients with DMT1 with low eGFR on the basis of micro- and macro-albuminuria.

\section{Abbreviations}

DKD: diabetic kidney disease; GFR: glomerular filtration rate; T2DM: type 2 diabetes mellitus; T1DM: type 1 diabetes mellitus; CKD: chronic kidney disease; HbA1c: glycated hemoglobin; LDL-c: low-density lipoprotein cholesterol; HDL-c: high density lipoprotein cholesterol; UAE: urinary albumin excretion measurements; BR: background retinopathy; PR: proliferative retinopathy; BP: blood pressure; ORs: odds ratios; ACE-Is: angiotensin converting enzyme inhibitors; ARBs: angiotensin II receptor antagonists; CV: cardiovascular; IDMS isotope dilution mass spectrometry.

\section{Authors' contributions}

$\mathrm{OL}, \mathrm{FV}, \mathrm{RP}, \mathrm{SDC}$ designed research; OL, RP, SDC performed research; OL, PG, RP SDC analyzed data; OL, RP, SDC wrote the paper; OL, FV. PF, AM, CG, AC, GR, $P G, R P, S D C$ reviewed the manuscript. All authors read and approved the final manuscript

\section{Author details}

${ }^{1}$ Unit of Endocrinology and Metabolic Diseases, Department of Surgical and Medical Sciences, University of Foggia, Foggia, Italy. ${ }^{2}$ Department of Internal Medicine, University of Genoa and Policlinico San Martino, Genoa, Italy. ${ }^{3}$ Department of Medicine, University of Padova, Padova, Italy. ${ }^{4}$ Department of Medical Sciences, Scientific Institute "Casa Sollievo della Sofferenza", San Giovanni Rotondo, FG, Italy. ${ }^{5}$ Diabetes and Metabolism Unit ASL Turin 5, Chieri, Italy. ${ }^{6}$ Institut d'Investigacions Biomèdiques August Pii Sunyer (IDIBAPS) and Centro de Investigación Biomédicaen Red de Diabetes y Enfermedades Metabólicas Asociadas (CIBERDEM), Barcelona, Spain. ${ }^{7}$ U.O. Diabetologia e Malattie Metaboliche, Multimedica IRCCS, Sesto San Giovanni, Milan, Italy.
${ }^{8}$ Department of Clinical and Experimental Medicine, University of Messina, Messina, Italy. ${ }^{9}$ Associazione Medici Diabetologi, Rome, Italy.

Acknowledgements

We thank the AMD-Annals Study Group.

Competing interests

The authors declare that they have no competing interests.

Availability of data and materials

All data generated or analysed during this study are included in this published article and its additional files.

\section{Consent for publication}

Not applicable.

Ethics approval and consent to participate

The study was approved by AMD Annals scientific committee.

Funding

Not applicable.

\section{Publisher's Note}

Springer Nature remains neutral with regard to jurisdictional claims in published maps and institutional affiliations.

Received: 17 February 2018 Accepted: 25 July 2018

Published online: 31 July 2018

\section{References}

1. American Diabetes Association. Standards of medical care in diabetes-2009. Diab Care. 2009:32(Suppl 1):S13-61.

2. Mogensen CE. Microalbuminuria, blood pressure and diabetic renal disease: origin and development of ideas. Diabetologia. 1999;42:263-85.

3. Maclsaac R, Tsalamandris C, Panagiotopoulos S, Smith TJ, McNeil KJ, Jerums $\mathrm{G}$. Nonalbuminuric renal insufficiency in type 2 diabetes. Diab Care. 2004:27:195-200

4. Kramer HJ, Nguyen QD, Curhan G, Hsu CY. Renal insufficiency in the absence of albuminuria and retinopathy among adults with type 2 diabetes mellitus. JAMA. 2003;289:3273-7.

5. Thomas MC, Macisaac RJ, Jerums G, Weekes A, Moran J, Shaw JE, Atkins RC. Nonalbuminuric renal impairment in type 2 diabetic patients and in the general population (national evaluation of the frequency of renal 
impairment co-existing with NIDDM [NEFRON] 11). Diabetes Care. 2009;32:1497-502.

6. Ninomiya T, Perkovic V, de Galan BE, Zoungas S, Pillai A, Jardine M, Patel A, Cass A, Neal B, Poulter N, Mogensen CE, Cooper M, Marre M, Williams B, Hamet P, Mancia G, Woodward M, Macmahon S, Chalmers J, ADVANCE Collaborative Group. Albuminuria and kidney function independently predict cardiovascular and renal outcomes in diabetes. J Am Soc Nephrol. 2009;20:1813-21.

7. Penno G, Solini A, Bonora E, Fondelli C, Orsi E, Zerbini G, Trevisan R, Vedovato M, Gruden G, Cavalot F, Cignarelli M, Laviola L, Morano S, Nicolucci A, Pugliese G, Renal Insufficiency And Cardiovascular Events (RIACE) Study Group. Clinical significance of nonalbuminuric renal impairment in type 2 diabetes. J Hypertens. 2011:29:1802-9.

8. Molitch ME, Steffes M, Sun W, Rutledge B, Cleary P, de Boer IH, Zinman B, Lachin J, Epidemiology of Diabetes Interventions and Complications Study Group. Development and progression of renal insufficiency with and without albuminuria in adults with type 1 diabetes in the diabetes control and complications trial and the epidemiology of diabetes interventions and complications study. Diab Care. 2010;33:1536-43.

9. Hill CJ, Cardwell CR, Patterson CC, Maxwell AP, Magee GM, Young RJ, Matthews B, O'Donoghue DJ, Fogarty DG. Chronic kidney disease and diabetes in the national health service: a cross-sectional survey of the UK national diabetes audit. Diabet Med. 2014;31:448-54.

10. Penno G, Russo E, Garofolo M, Daniele G, Lucchesi D, Giusti L, Sancho Bornez V, Bianchi C, Dardano A, Miccoli R, Del Prato S. Evidence for two distinct phenotypes of chronic kidney disease in individuals with type 1 diabetes mellitus. Diabetologia. 2017;60(6):1102-13.

11. Nicolucci A, Rossi MC, Arcangeli A, de Cimino A, Bigontina G, Fava D, Giorda C, Gentile S, Meloncelli I, Pellegrini F, Valentini U, Vespasiani G, AMD-Annals Study Group. Four year impact of a continuous quality improvement effort implemented by a network of diabetes outpatient clinics: the AMD Annals initiative. Diabet Med. 2010;27:1041-8.

12. De Cosmo S, Viazzi F, Pacilli A, Giorda C, Ceriello A, Gentile S, Russo G, Rossi MC, Nicolucci A, Guida P, Feig D, Johnson RJ, Pontremoli R, AMDAnnals Study Group. Serum uric acid and risk of CKD in type 2 diabetes. Clin J Am Soc Nephrol. 2015;10:1921-9.

13. Pacilli A, Viazzi F, Fioretto P, Giorda C, Ceriello A, Genovese S, Russo G, Guida P, Pontremoli R, De Cosmo S, AMD-Annals Study Group. Epidemiology of diabetic kidney disease in adult patients with type 1 diabetes in Italy: the AMD-Annals initiative. Diab Metab Res Rev. 2017;33(4):e2873.
14. Levey AS, Stevens LA, Schmid CH, Zhang YL, Castro AF 3rd, Feldman HI, Kusek JW, Eggers P, Van Lente F, Greene T, Coresh J, CKD-EPI (Chronic Kidney Disease Epidemiology Collaboration). A new equation to estimate glomerular filtration rate. Ann Intern Med. 2009;150:604-12.

15. Coresh J, Turin TC, Matsushita K, Sang Y, Ballew SH, Appel LJ, Arima H, Chadban SJ, Cirillo M, Djurdjev O, Green JA, Heine GH, Inker LA, Irie F, Ishani A, Ix JH, Kovesdy CP, Marks A, Ohkubo T, Shalev V, Shankar A, Wen CP, de Jong PE, Iseki K, Stengel B, Gansevoort RT, Levey AS. Decline in estimated glomerular filtration rate and subsequent risk of end-stage renal disease and mortality. JAMA. 2014;311(24):2518-31.

16. Thorn LM, Gordin D, Harjutsalo V, Hägg S, Masar R, Saraheimo M, Tolonen N, Wadén J, Groop PH, Forsblom CM, FinnDiane Study Group. The presence and consequence of nonalbuminuric chronic kidney disease in patients with type 1 diabetes. Diabetes Care. 2015;38:2128-33.

17. Caramori ML, Fioretto P, Mauer M. Low glomerular filtration rate in normoalbuminuric type 1 diabetic patients: an indicator of more advanced glomerular lesions. Diabetes. 2003;52:1036-40.

18. Cooper ME, Mundel P, Boner G. Role of nephrin in renal disease including diabetic nephropathy. Semin Nephrol. 2002;22:393-8.

19. Hoefield RA, Kalra PA, Baker PG, Sousa I, Diggle PJ, Gibson MJ, O'Donoghue DJ, Middleton RJ, New JP. The use of eGFR and ACR to predict decline in renal function in people with diabetes. Nephrol Dial Transplant. 2011;26:887-92

20. Fox CS, Matsushita K, Woodward M, Bilo HJ, Chalmers J, Heerspink HJ, Lee BJ, Perkins RM, Rossing P, Sairenchi T, Tonelli M, Vassalotti JA, Yamagishi K, de Coresh J, Jong PE, Wen CP, Nelson RG, Chronic Kidney Disease Prognosis Consortium. Associations of kidney disease measures with mortality and end-stage renal disease in individuals with and without diabetes: a meta-analysis. Lancet. 2012;380:1662-73.

21. Wu HY, Peng YS, Chiang CK, Huang JW, Hung KY, Wu KD, Tu YK, Chien $\mathrm{KL}$. Diagnostic performance of random urine samples using albumin concentration vs ratio of albumin to creatinine for microalbuminuria screening in patients with diabetes mellitus: a systematic review and meta-analysis. JAMA Intern Med. 2014;174:1108-15.

22. Pugliese G, Solini A, Fondelli C, Trevisan R, Vedovato M, Nicolucci A, Penno G, Renal Insufficiency And Cardiovascular Events (RIACE) Study Group. Reproducibility of albuminuria in type 2 diabetic subjects. Findings from the renal insufficiency and cardiovascular events (RIACE) study. Nephrol Dial Transplant. 2011;26:3950-4.
Ready to submit your research? Choose BMC and benefit from:

- fast, convenient online submission

- thorough peer review by experienced researchers in your field

- rapid publication on acceptance

- support for research data, including large and complex data types

- gold Open Access which fosters wider collaboration and increased citations

- maximum visibility for your research: over $100 \mathrm{M}$ website views per year

At BMC, research is always in progress.

Learn more biomedcentral.com/submissions 